UDC 347.211

BBC 67.404 .3

\title{
THE CONCEPT OF PARODY AS AN OBJECT OF COPYRIGHT
}

\author{
Tamara A. Kochubey \\ Volgograd State University, Volgograd, Russian Federation
}

Introduction: Parody is quite common in the contemporary art. The authors of parodies are getting fame due to the use of, sometimes quite broad, the material of the original copyrighted works. However, the generally accepted definition of "parody" is absent not only in the Civil Code, but also in the science. In this regard, there are quite legitimate questions: what are the legitimate limits of the implementation of parody in creativity? And how appropriate is the application of this copyright object within the limits of the national jurisdiction, as well as what are the criteria for its identification? The decision as to whether a work belongs to a parody is fully given to the courts. These arguments speak in favor of the relevance of the issues related to the definition of the concept of the copyright object, as well as its essential characteristics that determine the legal status and application.

Thus, the purpose of this study is the attempt to increase the scientific knowledge in terms of the legislative approaches to understanding parody as a type of creativity and the copyright object, by analyzing the domestic and foreign jurisprudence in this area, identifying its legal features and characteristics, followed by a proposal of the author's interpretation of the term "parody".

Methods: the methodological framework for this study, along with the general scientific dialectical method, is a set of logical (analysis, synthesis, deduction, induction) and legal (formal and legal, comparative law) methods.

Results: the author's proposal on the legislative consolidation of the notion "parody" in article 1274 of the Civil Code of the Russian Federation is scientifically substantiated. It is argued that the proposed legal measure will contribute to the formation of a uniform law enforcement practice and judicial enforcement in the resolution of disputes on recognizing parody as an object of copyright.

Conclusions: on the basis of the conducted research, the author identifies the main features of parody and formulates an original, scientific novelty definition of this concept as a meta-genre and an object of copyright, where the center of the new work is a recognizable original work, whose main features are exhibited in a critical comic light and appear in the form of a correspondence unregulated public relation between the author of the original and the parodist.

Key words: parody, product, copyright, literature, fair use.

УДК 347.211

ББК 67.404 .3

\section{ПОНЯТИЕ ПАРОДИИ КАК ОБЬЕКТА АВТОРСКОГО ПРАВА}

\author{
Тамара Александровна Кочубей \\ Волгоградский государственный университет, г. Волгоград, Российская Федерация
}

\footnotetext{
Введение: пародии довольно широко распространены в современном искусстве. Авторы пародий получают известность за счет использования, порой достаточно широкого, материала оригинальных произведений, охраняемых авторским правом. Однако общепринятое определение понятия «пародия» отсутis ствует не только в ГК РФ, но и в науке. В связи с этим возникают вполне закономерные вопросы: каковы ¿ легитимные пределы реализации пародии в творчестве? И насколько уместно обращение данного объекта авторского права в границах национальной юрисдикции, а также, каковы критерии его идентификации? Решение о том, относится ли то или иное произведение к пародии, полностью отдано на откуп судам. Перечисленные аргументы говорят в пользу актуальности вопросов, связанных с определением понятия данного объекта авторских прав, а также его сущностных характеристик, определяющих правовой статус и () режим его обращения.
} 
Таким образом, целью настоящего исследования является: попытка приращения научного знания в части законодательных подходов к пониманию пародии, как вида творчества и объекта авторского права, путем анализа отечественной и зарубежной судебной практики в данной сфере, выявления его правовых признаков и характеристик с последующим предложением авторской трактовки термина «пародия».

Методы: методологическую основу настоящего исследования, наряду с общенаучным диалектическим методом, составляет совокупность логических (анализ, синтез, дедукция, индукция) и юридических (формально-юридический, сравнительно-правовой) методов.

Результаты: научно обосновано предложение автора о законодательном закреплении в ст. 1274 ГК РФ понятия «пародия». Утверждается, что предложенная правовая мера будет способствовать формированию единообразной правоприменительной практики и судебному правоприменению при разрешении споров о признании того или иного объекта авторских прав пародией.

Выводы: на основе проведенного исследования автором выделяются основные признаки пародии и формулируется оригинальное, обладающее научной новизной определение данного понятия в качестве метажанра и объекта авторских прав, где в центре нового произведения находится узнаваемое оригинальное произведение, основные черты которого выставляются в критически-комическом свете и проявляются в виде заочного неурегулированного правом общественного отношения между автором оригинала и пародистом.

Ключевые слова: пародия, произведение, авторское право, литература, добросовестное использование.

\section{Введение}

Пародии являются весьма распространенным явлением в современной культуре. Сильный толчок к развитию этого жанра дало развитие Интернета, благодаря чему читатели получили возможность активно делиться впечатлениями о любимых героях того или иного произведения и обмениваться собственным творчеством на основе оригинала. На сетевом жаргоне этот жанр получил название fanfiction (от английского «фанатская литература»), в русскоязычном сегменте Интернета данный термин трансформировался в короткое слово «фанфик». Наиболее успешные произведения fanfiction публикуются большими тиражами, превращаясь в пародии, а их авторы приобретают широкую популярность. В качестве примера можно привести получившую большую известность на Западе книгу «Холестерин колец» Генри Берда и Дугласа Кенни - пародию на всемирно известную трилогию «Властелин колец» Дж. Толкина. А также пародии на мировой бестселлер «Гарри Поттер» Дж. Роулинг - серию книг о Тане Гроттер российского писателя Дмитрия Емеца, трилогию о Барри Троттере британского писателя Майкла Гербера и тетралогию о Порри Гаттере белорусских писателей Андрея Жвалевского и Игоря Мытько. Существуют также пародии на известные фильмы, песни и т. д.

\section{Законодательная позиция по вопросу определения понятия «пародия»}

Подход национального законодателя к определению понятия «пародия» как объекта авторского права представляется неоднозначным и расплывчатым.

В ГК РФ пародия упоминается только один раз: в п. 4 ст. 1274 законодатель разрешает создание произведения в жанре литературной, музыкальной либо другой пародии или в жанре карикатуры на основе иного (оригинального) правомерно обнародованного произведения и использование данных пародий или карикатуры без согласия автора либо другого обладателя исключительного права на оригинальное произведение и без выплаты ему вознаграждения. Однако в ГК РФ (да и в принципе в нормах действующего законодательства) отсутствует определение пародии.

Аналогичным образом обстоит ситуация и в европейском праве. Пародия упоминается только в пп. «k» П. 3 ст. 5 Директивы № 2001/29/ЕС Европейского парламента и Совета Европейского Союза «О гармонизации некоторых аспектов авторских и смежных прав в информационном обществе» в качестве исключения из механизма защиты авторских прав (без какого-либо определения исследуемого понятия). При этом следует отметить, что европейский законодатель приравнивает пародию к карикатуре и стилизации. 
Учитывая изложенное, можно согласиться с В.А. Колосовым, который считает, что по общему правилу пародию «следует понимать как термин в общеупотребительном значении» [2, с. 120]. С другой стороны, анализ позиций различных авторов наглядно демонстрирует, что у термина «пародия» такое общеупотребительное понимание отсутствует.

\section{Теоретическая дискуссия по вопросу определения понятия «пародия»}

В современной науке вопросы связи пародии и основного произведения является, как правило, предметом исследования работ по литературе и лингвистике. Немногочисленные работы, посвященные пародии как объектам авторских прав (например, диссертации В.Э. Фридман [15], Ю.В. Кулагина [3], Д. Борисенко [1]) фокусируют внимание на изучении вопросов его охраны, отдельных объектах авторских прав и их частях, упоминая о пародиях лишь вскользь, как об одном из возможных видов добросовестного использования произведения. В связи с этим представляется целесообразным провести анализ определений пародии, содержащихся в исследованиях различных филологов.

Так, А.В. Млечко определяет пародию следующим образом: «Пародия... выступает не столько как способ организации художественного материала, сколько как форма диалога с традицией... как своеобразная форма памяти не “крушение кумиров", не заполнение пустующих форм новым содержанием, но их творческое обыгрывание, вживление в их казавшуюся мертвой плоть новых смыслов» [7, с. 51-52].

Э. Ротермунд, рассматривая пародию в качестве самостоятельного жанра, определяет ее как «литературное произведение, которое перенимает на себя формально-стилистические элементы, часто также предмет повествования, какого-либо произведения любого жанра, но заимствованное может быть частично изменено так, что перед нами предстает отчетливое расхождение между отдельными структурными пластами» [18, р. 48].

По мнению Г.И. Лушниковой пародия представляет собой вторичный жанр, «когнитивную метафору пародируемого объекта в том смысле, что она преобразует, трансфор- мирует прототекст, репрезентируя его ведущие черты в критически-комическом свете. Пародия дает новый взгляд, новое видение пародируемого текста, она подразумевает сравнение пародирующего и пародируемого, в результате которого создается... критическая и одновременно комическая интерпретация прототекста» [6, с. 225].

Как отмечает О.А. Сысоева, пародия представляет собой уже метажанр, «в котором доминирующей является авторская установка на определенный тип общения с адресатом; объектом изображения пародии является другое произведение, художественные приемы какого-либо писателя, тематика, идейное содержание, жанр, целое литературное направление и тому подобное, целью - эстетическая критика указанного объекта, осуществляемая средствами иронической стилизации» [14, с. 334].

Л. Хатчин, разграничивая пародию и сатиру, пишет, что «сатира использует критическую дистанцию для того, чтобы отрицательно охарактеризовать реальность, тогда как современная пародия в ироническом сопоставлении двух текстов негативного отношения к пародируемому тексту не предполагает. Интенция сатиры - реальность, интенция пародии - текст» [17].

В приведенных выше понятиях ученых лингвистов наблюдается, что пародия и сатира близко коррелируют и направлены на высмеивание.

Учитывая изложенное, приходится согласиться с Р.Л. Лукьяновым, отметившим невозможность толкования в правовых отношениях термина «пародия» без каких-либо оговорок, в том варианте, который предлагают филологи [5, с. 7$]$.

В подтверждение понятиям ученых филологов Д. Липцик утверждает о том, что «пародия является шуточной имитацией серьезного произведения» [4].

Представляется, что именно понимание пародии, как метажанра, наиболее соответствует истине. Как самостоятельный жанр пародию мешают воспринимать, прежде всего, существенные заимствования из оригинала. В то же время, пародию нельзя считать и полностью вторичной, поскольку порой автор пародии достаточно серьезно перерабатыва- 
ет оригинальное произведение, оставляя только те пародируемые моменты, которые обеспечивают узнаваемость. Напротив, метажанр, особенностью которого является именно смешение различных стилей, наиболее точно отражает суть пародии, которая выходит за границы жанра оригинала.

Таким образом, развернувшаяся в работах правоведов и филологов дискуссия не позволяет сформировать четкого единообразного теоретического подхода к определению понятия «пародия» как объекта авторского права, вследствие чего в случае возникновения спорного отношения в каждой конкретной ситуации вопрос о том, является ли конкретное произведение пародией, остается на усмотрение суда.

\section{Судебное толкование понятия «пародия» как объекта авторского права в России и за рубежом}

ФАС Московского округа в постановлении от 09.11.2011 по делу № А40-125210/09110-860 выявил два главных признака пародии: «пародия неизменно связана с комическим эффектом и должна быть сразу же узнаваема, соответственно, пародия не может быть совершенно отделена от оригинального произведения» [10]. При этом суд отметил, что правообладатель оригинального произведения не вправе запретить создавать пародии лишь на том основании, что изменяются какие-то части произведения, оставляя неизменными другие части.

Аналогичная позиция была сформулирована и в решении Арбитражного суда г. Москвы от 23.09.2015 по делу № А40-15245/2015. Суд указал, что комический эффект достигается путем узнаваемости телезрителями содержания видеоклипа [13]. По другому делу суд, напротив, указал, что поскольку изображение быстровозводимого дома, размещенного в рамках карикатуры, не является юмористическим, в котором создается преувеличение или заострение характерных черт, не деформирует визуальное восприятие дома; незначительное изменение изображения не является существенным изменением конструктивной формы изображения; изображение полностью идентично изображению быстровозво- димых домов, построенных по технологии ЗАО «ИНСИ», то п. 3 ст. 1274 ГК РФ не подлежит применению [12].

Президиум Высшего арбитражного суда РФ в постановлении от 19.11.2013 № 5861/13 по делу № А40-38278/2012-12-166 отметил, что «любая пародия представляет собой новое произведение, созданное в результате переработки оригинального произведения... При создании пародии первоначальное оригинальное произведение должно быть в центре нового, а не быть его фоном или вспомогательным средством» [9]. Однако в особом мнении к данному судебному акту судья Е.Ю. Валявина выделила в качестве основных критериев пародии сатирическое подражание и узнаваемость.

Аналогичный подход наблюдается и в европейской практике. Так, в деле «Johan Deckmyn and Others v. Helena Vandersteen and Others» Европейский суд указал, что «пародия должна рассматриваться в качестве произведения, обладающего следующими характеристиками: 1) использованием в рамках пародийного произведения существующего произведения с одновременными значительными различиями; 2) носить юмористический характер» [16].

В качестве примера практики судов США приведем дело «Suntrust Bankv. Houghton Mifflin Company» [19], в котором исследовался спор о легальности литературного произведения «Ветер стих», основанного на бестселлере «Унесенные ветром». Основным аргументом защиты являлся пародийный характер романа, и суд встал на сторону защиты. По данному делу суд, несмотря на пародийную суть оспариваемого романа, отметил, что пародию следует отличать от сатиры, поскольку она комментирует либо критикует оригинал, но не акцентировал внимание на наличии или отсутствии юмористического элемента. Такие цели, как комментирование и критика, положены в основу формулировки понятия «добросовестное использование оригинального произведения» (наряду с использованием в новостях, обучении, школьных программах и исследованиях), и в силу параграфа 107 раздела 17 Кодекса США не являются нарушением авторских прав.

Как правило, суд не ограничивается собственным аудиовизуальным восприятием ос- 
париваемого произведения на основе оригинала, а дополнительно назначает его экспертизу. Так, например, по делу № A40-60254/2012 эксперт в своем заключении указал, что музыкальные произведения с текстом «Будь или не будь», «Перелетная птица», использованные в телепередаче «Оливье шоу», носит пародийный характер. Номера являются и принадлежат особому жанру музыкальной пародии, пародируют песню в целом и ее исполнителей, используя их узнаваемость и популярность, а не ее музыкальный материал (собственно музыку, мелодию песни). Пародийный эффект номеров складывается из ряда компонентов - популярности музыки, визуального ряда, широкой популярности исполнителей и нового текста юмористического содержания в их сочетании. Если хотя бы один из названных компонентов, в том числе узнаваемость популярной музыки, отсутствует, то пародийный эффект просто исчезает [8].

Суды также подчеркивают, что закон не оговаривает, каковы пределы заимствования оригинального произведения при создании пародийного произведения. Закон прямо устанавливает, что пародийное произведение создается на основе другого (оригинального), то есть при пародии допускается как частичная, так и полная переработка оригинального произведения, либо использование частей оригинального [11].

\section{Выводы}

Резюмируя, можно выделить следующие основные сущностные признаки пародии как объекта авторского права:

1) метажанровое содержание - это характеристика пародии является ее сущностью, поскольку пародия создается на основе слияния различных литературных (музыкальных и т. д.) жанров, а также путем трансформации оригинала в новое произведение (пародии характеризуются в судебных актах исключительно как самостоятельные произведения);

2) узнаваемость - первоначальное оригинальное произведение должно быть в центре нового;

3) юмористический характер - основные черты оригинала выставляются в критически-комическом свете. При этом отметим в скобках, что американская судебная практи- ка не считает данный критерий обязательным, указывая, что пародия должна комментировать или критиковать оригинал;

4) заимствование - трансформация, искажение оригинального произведения физическим лицом в новый объект авторского права без специального разрешения автора оригинала. Наблюдается некая взаимосвязь между двумя произведениями, которые фактически друг без друга не существуют.

Таким образом, в целях формирования единообразной правоприменительной практики и устранения проблемы неоднозначности судебного толкования рекомендуется законодательно закрепить понятие «пародия» в ст. 1274 ГК РФ.

Между тем данное понятие еще требует существенной проработки. На сегодняшний день под пародией следует понимать метажанр, где в центре нового произведения находится узнаваемое оригинальное произведение, основные черты которого выставляются в критически-комическом свете, а его юридическая сущность как объекта авторских прав проявляется в виде заочного, неурегулированного правом общественного отношения между автором оригинала и пародистом.

Важно отметить, что положения ст. 1274 ГК РФ должны служить правомерному использованию чужого произведения в своих коммерческих целях. При этом следует помнить о том, что получение иска о нарушении исключительного права может быть спровоцировано недобросовестным заимствованием, которое будет наблюдаться в слабом пародийном элементе, но в колоссальном заимствовании чужого произведения.

\section{СПИСОК ЛИТЕРАТУРЫ}

1. Борисенко, Д. Права на результаты интеллектуальной деятельности в составе аудиовизуального произведения : дис. ... канд. юрид. наук / Борисенко Диана. - М., 2013. - 190 с.

2. Колосов, В. А. Пародия в системе авторского права / В. А. Колосов // Закон. - 2013. - № 9. -С. 120-132.

3. Кулагин, Ю. В. Ограничения субъективных авторских прав по законодательству России и отдельных зарубежных стран : дис. ... канд. юрид. наук / Кулагин Юрий Валерьевич. - М., 2010. - 171 с.

4. Липцик, Д. Авторское право и смежные права / Д. Липцик. - М. : Ладомир : Изд-во ЮНЕСКО, 2002. -794 c. 
5. Лукьянов, Р. Л. Гражданско-правовой режим охраны пародии / Р. Л. Лукьянов // Право интеллектуальной собственности. - 2012. - № 1 (21). C. 5-8.

6. Лушникова, Г. И. Когнитивные и лингво-стилистические особенности литературной пародии : дис. ... д-ра филол. наук / Лушникова Галина Игоревна. - Кемерово, 2010. - 250 с.

7. Млечко, А. В. Игра, метатекст, трикстер: пародия в «русских» романах В.В. Набокова / А. В. Млечко. - Волгоград : Изд-во ВолГУ, 2000. - 188 с.

8. Постановление Девятого арбитражного апелляционного суда от 12.07.2013 № 09АП-19034/ 2013-ГК по делу № А40-60254/2012. - Доступ из справ.-правовой системы «КонсультантПлюс».

9. Постановление Президиума ВАС РФ от 19.11.2013 № 5861/13 по делу № А40-38278/2012-12166. - Доступ из справ.-правовой системы «КонсультантПлюс».

10. Постановление ФАС Московского округа от 09.11.2011 по делу № А40-125210/09-110-860 // СПС «Консультант Плюс». - Доступ из справ.правовой системы «КонсультантПлюс».

11. Решение Арбитражного суда г. Москвы от 05.06.2012 по делу № А40-38278/2012. - Доступ из справ.-правовой системы «КонсультантПлюс».

12. Решение Арбитражного суда г. Москвы от 14.10.2013 по делу № А40-97672/2012. - Доступ из справ.-правовой системы «Консультант Плюс».

13. Решение Арбитражного суда г. Москвы от 23.09.2015 по делу № А40-15245/2015. - Доступ из справ.-правовой системы «Консультант Плюс».

14. Сысоева, О. А. Литературная пародия: проблема жанра / О. А. Сысоева // Вестник Нижегородского университета им. Н.И. Лобачевского. - 2013. № 5 (1). - С. 330-335.

15. Фридман, В. Э. Охрана частей и структурных элементов произведения как объектов авторского права в России и США : дис. ... канд. юрид. наук / Фридман Вероника Эмильевна. - М., 2005. 142 с.

16. Johan Deckmyn and Others v. Helena Vandersteen and Others, Case C-201/13, ECJ. Electronic text data. - Mode of access: http://curia. europa.eu/juris/liste.jsf?num=C-201/13 (date of access: 22.10.2017). - Title from screen.

17. Hutcheon, L. Irony, Nostalgia, and the Postmodern / L. Hutcheon. - Electronic text data. Mode of access: http://www.library.utoronto.ca/utel/ criticism/hutchinp.html (date of access: 22.10.2017). Title from screen.

18. Parodie. Arbeitstexte fuer den Unterricht. Stuttgart : Philipp Reclam jun., 1989. - 80 p.

19. Suntrust Bank v. Houghton Mifflin Company, 268 F3d 1257 (11th Cir, 2001). - Electronic text data. Mode of access: https://openjurist.org/268/f3d/1257 (date of access: 22.10.2017). - Title from screen.

\section{REFERENCES}

1. Borisenko D. Prava na rezultaty intellektualnoy deyatelnosti $v$ sostave audiovizualnogo proizvedeniya: dis. ... kand. yurid. nauk [The Rights to the Results of Intellectual Activity in the Composition of Audiovisual Works. Cand. jurid. sci. diss.]. Moscow, 2013. $190 \mathrm{p}$.

2. Kolosov V.A. Parodiya v sisteme avtorskogo prava [Parody in the Copyright Law]. Zakon, 2013, no. 9 , pp. 120-132.

3. Kulagin Yu.V. Ogranicheniya subyektivnykh avtorskikh prav po zakonodatelstvu Rossii $i$ otdelnykh zarubezhnykh stran: dis. ... kand. yurid. nauk [The Limitations of Copyright According to the Legislation of Russia and Some Foreign Countries. Cand. jurid. sci. diss.]. Moscow, 2010. $171 \mathrm{p}$.

4. Liptsik D. Avtorskoe pravo i smezhnye prava [Copyright and Allied Rights]. Moscow, Ladomir Publ.; Izd-vo YuNESKO, 2002. 794 p.

5. Lukyanov R.L. Grazhdansko-pravovoy rezhim okhrany parodii [The Civil-Legal Regime for the Protection of Parody]. Pravo intellektualnoy sobstvennosti, 2012, no. 1 (21), pp. 5-8.

6. Lushnikova G.I. Kognitivnye $i$ lingvostilisticheskie osobennosti literaturnoy parodii: dis. ... d-ra filol. nauk [Cognitive and Linguo-Stylistic Peculiarities of a Literary Parody. Cand. philol. sci. diss.]. Kemerovo, 2010. 250 p.

7. Mlechko A.V. Igra, metatekst, trikster: parodiya $v$ «russkikh» romanakh V.V. Nabokova [Game, Metatext, Trickster: the Parody in the Russian Novels by Vladimir Nabokov]. Volgograd, Izd-vo VolGU, 2000. $188 \mathrm{p}$.

8. Postanovlenie Devyatogo arbitrazhnogo apellyatsionnogo suda ot 12.07.2013 № 09AP19034/2013-GK po delu № A40-60254/2012 [The Decree of the Ninth Arbitration Appeal Court of July 12, 2013 on Case no. A40-60254/2012]. Access from Reference Legal System "KonsultantPlyus".

9. Postanovlenie Prezidiuma VAS RF ot 19.11.2013 № 5861/13 po delu № A40-38278/201212-166 [Decree of the Presidium of the Higher Arbitration Court of the Russian Federation of November 19, 2013 no. 5861/13 on Case no. A40-38278/ 2012-12-166]. Access from Reference Legal System "KonsultantPlyus".

10. Postanovlenie FAS Moskovskogo okruga ot 09.11.2011 po delu № A40-125210/09-110-860 [The Decree of the Federal Arbitration Court of the Moscow District of November 9, 2011 on Case no. A40-125210/ 09-110-860]. Access from Reference Legal System "KonsultantPlyus".

11. Reshenie Arbitrazhnogo suda g. Moskvy ot 05.06.2012 po delu № A40-38278/2012 [The 
Decision of the Arbitration Court of Moscow of June 5, 2012 on Case no. A40-38278/2012]. Access from Reference Legal System "KonsultantPlyus".

12. Reshenie Arbitrazhnogo suda g. Moskvy ot 14.10.2013 po delu № A40-97672/2012 [The Decision of the Arbitration Court of Moscow of October 14, 2013 on Case no. A40-97672/2012]. Access from Reference Legal System "KonsultantPlyus".

13. Reshenie Arbitrazhnogo suda g. Moskvy ot 23.09.2015 po delu № A40-15245/2015 [The Decision of the Arbitration Court of Moscow of September 23, 2015 on Case no. A40-15245/2015]. Access from Reference Legal System "Konsultant Plyus".

14. Sysoeva O.A. Literaturnaya parodiya: problema zhanra [Literary Parody: the Problem of Genre]. Vestnik Nizhegorodskogo universiteta im. N.I. Lobachevskogo, 2013, no. 5 (1), pp. 330-335.
15. Fridman V.E. Okhrana chastey i strukturnykh elementov proizvedeniya kak obyektov avtorskogo prava $v$ Rossii i SShA: dis. ... kand. yurid. nauk [Protection of Parts and Structural Elements of Works as Objects of Copyright in Russia and the USA. Cand. jurid. sci. diss.]. Moscow, 2005. 142 p.

16. Johan Deckmyn and Others v. Helena Vandersteen and Others, Case C-201/13, ECJ. URL: http://curia.europa.eu/juris/liste.jsf?num $=C-201 / 13$ (accessed October 22, 2017).

17. Hutcheon L. Irony, Nostalgia, and the Postmodern. URL: http://www.library.utoronto.ca/utel/ criticism/hutchinp.html (accessed October 22, 2017).

18. Parodie. Arbeitstexte fuer den Unterricht. Stuttgart, Philipp Reclam jun., 1989. 80 p.

19. Suntrust Bank v. Houghton Mifflin Company, 268 F3d 1257 (11th Cir, 2001). URL: https://openjurist. org/268/f3d/1257 (accessed October 22, 2017).

\section{Information about the Author}

Tamara A. Kochubey, Master Student, Department of Civil and International Private Law, Volgograd State University, Base Department of the Southern Scientific Center of the Russian Academy of Sciences, Prosp. Universitetsky, 100, 400062 Volgograd, Russian Federation, gimchp@volsu.ru.

\section{Информация об авторе}

Тамара Александровна Кочубей, магистрант кафедры гражданского и международного частного права, Волгоградский государственный университет, базовая кафедра ЮНЦ РАН, просп. Университетский, 100, 400062 г. Волгоград, Российская Федерация, gimchp@volsu.ru. 